\title{
Transcutaneously measured near-infrared spectro- scopic liver tissue oxygenation does not correlate with hepatic venous oxygenation in children
}

\author{
[La mesure transcutanée de l'oxygénation du tissu hépatique par spectroscopie proche \\ infrarouge ne correspond pas à l'oxygénation hépatique veineuse chez les enfants] \\ Markus Weiss MD, ${ }^{*} \dagger$ Gabriele Schulz MD, ${ }^{*} \mathbb{S}$ Margrit Fasnacht MD, $\ddagger$ Christian Balmer MD, $\ddagger$ \\ Joachim E. Fischer MD MS, * Andreas C. Gerber MD, $†$ Hans-Ulrich Bucher MD, $\$$ Oskar Baenziger MD*
}

Purpose: To compare transcutaneous near-infrared spectroscopic (NIRS) measured liver tissue oxygenation with hepatic vein oxygen saturation $\left(\mathrm{SvhO}_{2}\right)$ in children undergoing cardiac catheterization.

Methods: A NIRS optode (containing an emitter and a receiver of near-infrared light) was placed directly below the right costal arch above the palpable liver in 40 children aged 0.02 to $7.28 \mathrm{yr}$ (median: $1.8 \mathrm{yr}$ ). Spatially resolved spectroscopic measured tissue oxygenation index (TOI) was recorded using the NIRO-300 ${ }^{\mathrm{TM}}$. Paired blood samples from the hepatic vein were taken under radiological control for determination of $\mathrm{SvhO}_{2}$ in a co-oxymeter. TOI values were compared with hepatic vein oxygenation, with simultaneously obtained arterial oxygen saturation $\left(\mathrm{SaO}_{2}\right)$, inferior vena cava $\mathrm{SO}_{2}$ and hemoglobin concentration using simple linear and multi-regression analysis.

Results: TOI values ranged from 35\% to $73 \%$ (58.6 $\pm 8.4 \%$ ); $\mathrm{SvhO}_{2}$ from $32 \%$ to $80 \%$ (58.4 $\left.\pm 14.4 \%\right)$, and arterial $\mathrm{SO}_{2}$ from $54 \%$ to $100 \%$ (90.0 $\pm 11.4 \%)$. TOI and hepatic vein oxygen saturation failed to correlate $(r=0.052 / P=0.752)$. A regression model containing arterial saturation $\left(\Delta \mathrm{R}^{2}=0.177\right)$ and the ratio of pulmonary to systemic resistance $\left(\Delta R^{2}=0.095\right)$ explained $27.3 \%$ of the observed variance in TOI. In this model, hepatic vein oxygen saturation was no longer significant; explaining only $3.4 \%$ of the variance. No other variable retained a significant association.

Conclusion: Transcutaneously measured NIRS tissue oxygenation with an optode placed over the palpable liver does not correlate with $\mathrm{SvhO}_{2}$. The value is dominated by non-hepatic variables such as arterial saturation and vascular resistances.
Objectif : Comparer la mesure transcutanée de l'oxygénation du tissu hépatique par spectroscopie proche infrarouge (SPIR) à la saturation en oxygène du sang veineux hépatique $\left(\mathrm{SO}_{2} v h\right)$ chez des enfants devant subir un cathétérisme cardiaque.

Méthode : Une optode de SPIR (contenant un émetteur et un récepteur de lumière proche infrarouge) a été placée directement sous le rebord costal droit au-dessus du foie palpable chez 40 enfants de 0,02 à 7,28 ans (médiane : 1,8 an). La mesure spectroscopique à résolution spatiale de l'index d'oxygénation tissulaire (IOT) a été enregistrée en utilisant le NIRO-300 ${ }^{\mathrm{Tm}}$. Des échantillons sanguins jumelés obtenus de la veine hépatique ont été prélevés sous surveillance radiologique pour la détermination de la $\mathrm{SO}_{2}$ vh dans un cooxymètre. Les valeurs d'IOT ont été comparées avec l'oxygénation de la veine hépatique, avec la saturation en oxygène du sang artériel prélevé simultanément $\left(\mathrm{SaO}_{2}\right)$, la $\mathrm{SO}_{2}$ de la veine cave inférieure et la concentration d'hémoglobine en utilisant une analyse linéaire simple et une analyse à régression multiple.

Résultats : Les valeurs d'IOT allaient de $35 \%$ à $73 \%$ (58,6 \pm $8,4 \%)$; la $\mathrm{SO}_{2}$ vh, de $32 \%$ à $80 \%(58,4 \pm 14,4 \%)$ et la $\mathrm{SO}_{2}$ artérielle, de $54 \%$ à $100 \%(90,0 \pm 11,4 \%)$. L'IOT et la saturation en oxygène du sang veineux hépatique n'ont pas démontré de corrélation ( $r=0,052 / P=0,752)$. Un modèle de régression contenant la saturation artérielle $\left(\Delta R^{2}=0,177\right)$ et le ratio de la résistance pulmonaire à la résistance générale $\left(\Delta R^{2}=0,095\right)$ ont permis d'expliquer $27,3 \%$ de la variance observée pour l'IOT. Dans ce modèle, la saturation en oxygène du sang hépatique n'était plus significative, expliquant seulement 3,4\% de la variance. Aucune autre variable n'a conservé d'association significative.

Conclusion : L'oxygénation tissulaire par SPIR transcutanée avec une optode placée sur le foie palpable ne démontre pas de corrélation avec

From the Departments of Intensive Care and Neonatology, ${ }^{*}$ Anaesthesia, $†$ and Cardiology, $\ddagger$ University Children’s Hospital, and the Clinic of Neonatology, $\$$ University Hospital, Zurich, Switzerland.

Address correspondence to: Dr. Markus Weiss, Department of Anaesthesia and Department of Intensive Care and Neonatology,

University Children's Hospital, Steinwiesstrasse 75, 8032 Zurich, Switzerland. Phone: +41 126671 11; Fax:+41 12667994 ;

E-mail: markus.weiss@kispi.unizh.ch

Support: The study was supported by a Grant of the Swiss National Foundation, Grant No. 32-56713.99

Accepted for publication March 28, 2002

Revision accepted June 7, 2002. 
la $\mathrm{SO}_{2}$ vh. La valeur est dominée par des variables non hépatiques comme la saturation artérielle et les résistances vasculaires.

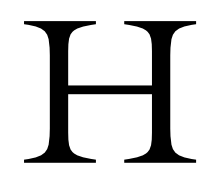

EPATO-SPLANCHNIC blood flow, gut mucosal oxygenation, splanchnic ischemia and gut hypoxia play an important role in the pathogenesis of shock, sepsis and multiple organ failure. ${ }^{1,2}$ During shock, adaptive mechanisms redistribute blood flow in favour of the brain and the heart, while blood supply to the splanchnic region is curtailed. This mechanism imposes a particularly high risk of ischemia upon the splanchnic region during periods of decreased cardiac output. Therefore, monitoring hepato-splanchnic tissue oxygenation by means of a hepatic vein catheter or gastric tonometry are promising potential strategies for early detection of deteriorating regional tissue oxygenation that may herald impending shock and global tissue hypoxia. ${ }^{3-6}$

However, hepatic vein catheters require the invasive insertion of devices. In newborns and infants particularly, the risks associated with this invasiveness would not outweigh the potential benefits of monitoring. In contrast, near-infrared spectroscopy (NIRS) is a non-invasive method for continuous, transcutaneous monitoring of tissue oxygenation. ${ }^{7,8}$ In neonates and children up to eight years, the liver represents an organ within the splanchnic region that is of homogenous tissue. Access for transcutaneous NIRS measurements can easily be obtained by placing the transducer below the right costal arch. ${ }^{9,10}$ In animal investigations, this method allowed the monitoring of hepatic vein oxygen saturation $\left(\mathrm{SvhO}_{2}\right)$ as an indicator of splanchnic oxygen utilization. ${ }^{11}$ However, data systematically assessing the validity of this assumption in children are not available.

Therefore, we compared transcutaneous NIRS measured tissue oxygenation by an optode placed over the palpable liver with $\mathrm{SvhO}_{2}$ in infants and children undergoing cardiac catheterization for diagnostic assessment of congenital cardiac malformations. Due to the underlying conditions, this patient group provided a wide spectrum of systemic saturations and $\mathrm{SvhO}_{2}$.

\section{Methods}

With approval of the local Ethics Committee and informed parental consent, we studied 40 children up to eight years of age with cyanotic or non-cyanotic cardiac diseases scheduled for diagnostic cardiac catheterization under general anesthesia.
On each patient a NIRS probe (Hamamatsu, Photonics, Japan), consisting of a near-infrared light emitter optode and a receiver optode, was placed below the right costal arch on the skin overlying the palpable liver (Figure). Emitter and receiver optodes were secured to the body by elastic tapes and were inserted into a black probe receptacle to provide an interoptode distance of $40 \mathrm{~mm}$ and to shield the optodes from light. Quantitative tissue oxygenation index (TOI) representing the ratio of oxygenated hemoglobin $\left(\mathrm{HbO}_{2}\right)$ to total hemoglobin $\left[\mathrm{HbO}_{2}+\right.$ deoxygenated hemoglobin ( $\mathrm{HHB})]$ was measured and calculated using spatially resolved spectroscopy (SRS) with the NIRO-300 ${ }^{\mathrm{TM}}$ device (Hamamatsu, Photonics, Japan). The underlying technical principles of SRS allow calculation of absolute tissue oxygenation values without knowledge of tissue path-length. The methods have been described in detail by Matcher et al. and Suzuki et al. ${ }^{12,13}$

A standardized general anesthesia technique was provided for all patients using sevoflurane in oxygen and nitrous oxide and atracurium for muscle paralysis. The patients' trachea were intubated and the lungs ventilated with intermittent positive pressure ventilation and a positive end-expiratory pressure of $5 \mathrm{~cm}$ $\mathrm{H}_{2} \mathrm{O}$. After establishing a femoral venous access, the cardiologist inserted a distally curved NIH cardiac catheter (Cook, Bjaeverskov, Denmark) into a right hepatic vein under radiological control and paired blood samples were withdrawn slowly (to avoid infracaval contamination). $\mathrm{SvhO}_{2}$ and hemoglobin concentration were determined immediately after withdrawal (Oxymeter OSM 3; Radiometer, Copenhagen, Denmark). TOI measurements were performed simultaneously at a sample rate of two seconds. Hemodynamic and respiratory data were recorded from the anesthesia monitor. Subsequent blood samples for oxymetry and invasive pressure readings were obtained from the inferior vena cava (IVC), superior vena cava, left atrium, aorta and from the pulmonary artery, as required by the diagnostic cardiac catheterization procedure.

TOI was calculated as the median value of 30 measurements (one minute) during the period of sampling from the hepatic vein for each of two repeat samples. The final values entered into the analysis were the means of the two TOI values, the two oxygen saturations and the two hemoglobin concentration measurements obtained from the paired samples. Systemic cardiac index (Qs), and systemic and pulmonary vascular resistance ( $\mathrm{Rs}$; Rp) were calculated using the Fick formula. 


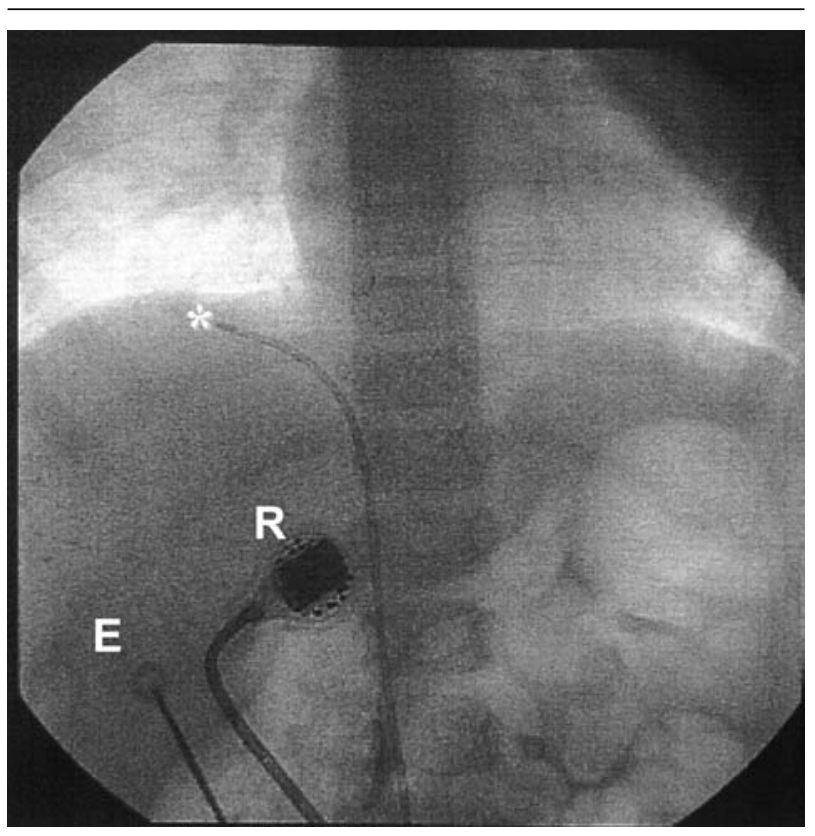

FIGURE Antero-posterior $x$-ray of the upper abdominal area with cardiac catheter tip ${ }^{*}$ ) in a right-sided hepatic vein. The near-infrared spectroscopy (NIRS) probe containing an emitter optode $(\mathrm{E})$ and a receiver optode $(\mathrm{R})$ is attached over the palpable liver just below the costal arch.

\section{Data analysis}

Data are presented as range (mean $\pm \mathrm{SD}$ ). Pearson's correlation coefficients and $P$-values from linear regression analysis were calculated between TOI and hepatic vein, inferior caval vein and arterial oxygen saturation, hemoglobin concentration and calculated hemodynamic data such as Qs, Rs and Rp. Multivariable regression models with TOI as the dependent variable and the variables listed above as independent variables were performed using general linear models. These models checked for potential confounding of the possible relation between TOI and hepatic vein saturation by mean arterial blood pressure, heart rate, central venous pressure, hemoglobin concentration, temperature, and ventilator settings including expiratory gases. A $P<0.05$ was considered statistically significant. Calculations were performed using SAS software (version 8.1, SAS Inc, Cary, NC, USA).

\section{Results}

Twenty cyanotic and twenty non-cyanotic pediatric cardiac patients, aged 0.02 to $7.3 \mathrm{yr}$ (median: $1.8 \mathrm{yr}$ ) were studied. Half of the patients were girls. Demographic data are presented in the Table.
TABLE Demagraphic, physiological and laboratory data $(n=40$ patients)

\begin{tabular}{|c|c|c|}
\hline & Units & $\begin{array}{l}\text { Median or mean } \pm S D \\
\text { (range) }\end{array}$ \\
\hline Patient age & $\mathrm{yr}$ & $1.81(0.02-7.28)$ \\
\hline Body weight & $\mathrm{kg}$ & $9.55(2.9-23.0)$ \\
\hline Body length & $\mathrm{cm}$ & $80.5(50.0-123.0)$ \\
\hline $\begin{array}{l}\text { Mean hemoglobin } \\
\text { concentration }\end{array}$ & $g \cdot L^{-1}$ & $\begin{array}{l}118.2 \pm 20.6 \\
(91.5-171.0)\end{array}$ \\
\hline Heart rate & beats. $\min ^{-1}$ & $107.9 \pm 15.1(75-130)$ \\
\hline Mean arterial pressure & $\mathrm{mmHg}$ & $57.0 \pm 8.0(41.7-82.0)$ \\
\hline Central venous pressure & $\mathrm{mmHg}$ & $5.6 \pm 1.7(3.0-11.0)$ \\
\hline Mean TOI* & $\%$ & $58.6 \pm 8.4(34.5-72.5)$ \\
\hline Mean hepatic venous $\mathrm{SO}_{2}{ }^{* *}$ & $\%$ & $58.4 \pm 14.4(32.1-80.6)$ \\
\hline Arterial $\mathrm{SO}_{2}{ }^{* *}$ & $\%$ & $90.0 \pm 11.4(54.0-100.0)$ \\
\hline Inferior vena cava $\mathrm{SO}_{2}{ }^{* *}$ & $\%$ & $68.6 \pm 13.2(38.0-90.0)$ \\
\hline $\begin{array}{l}\text { Pulmonary vascular } \\
\text { resistance (Rp) } \\
\text { Systemic vascular }\end{array}$ & $\mathrm{U} \cdot \mathrm{m}^{2}$ & $1.9 \pm 0.8(0.8-3.3)$ \\
\hline resistance (Rs) & $\mathrm{U} \cdot \mathrm{m}^{2}$ & $14.3 \pm 6.3(4.4-32.3)$ \\
\hline Ratio Rp/Rs & -- & $0.2 \pm 0.1(0.0-0.4)$ \\
\hline Systemic cardiac output & $\mathrm{L} \cdot \mathrm{min}^{-1} \cdot \mathrm{m}^{2}$ & $4.5 \pm 2.1(1.9-10.1)$ \\
\hline
\end{tabular}

*TOI $=$ tissue oxygenation index; ${ }^{*} \mathrm{SO}_{2}=$ oxygen saturation.

TOI values ranged from $35 \%$ to $73 \%(58.6 \pm 8.4 \%)$, $\mathrm{SvhO}_{2}$ from $32 \%$ to $80 \%(58.4 \pm 14.4 \%)$ and arterial oxygenation saturation from $54 \%$ to $100 \%(90.0 \pm$ $11.4 \%$; Table). Fluctuations of the 30 TOI values due to the respiratory-related liver movements during the $60 \mathrm{sec}$ recording period, were less than $3 \%$. Agreement (bias/precision) between the paired TOI measurements was $0.3 \% / 2.4 \%$ and between the two $\mathrm{SvhO}_{2}$ and hemoglobin measurements were $0.2 \% / 8 \%$ and $-0.7 / 11.2 \mathrm{~g} \cdot \mathrm{L}^{-1}$ respectively.

There was no correlation between TOI and $\mathrm{SvhO}_{2}$ (all patients $\mathrm{r}=0.052 / P=0.752$; cyanotic cardiac patients $(n=20) \mathrm{r}=0.17 \mathrm{l} / P=0.472$; non-cyanotic cardiac patients $[(n=20) \mathrm{r}=0.27 / 0.263]$. Simple linear regression analysis revealed significant associations between TOI and arterial oxygen saturation $(r=0.39$, $P=0.014)$ and the ratio of pulmonary to systemic vascular resistance $r=-0.36, P=0.03)$. There was a trend towards an association between TOI and the oxygen saturation in the IVC $(\mathrm{r}=0.30, P=0.08)$, as well as with length and weight (both $\mathrm{r}=0.28, P=0.07$ ), with systemic vascular resistance $(\mathrm{r}=0.29, P=0.07)$, and with systemic cardiac output $(\mathrm{r}=-0.30, P=0.059)$.

Multivariable regression revealed that after considering arterial saturation and the ratio of pulmonary to systemic vascular resistance, which together explained $27.3 \%$ of the variance in TOI, no other variable significantly improved the model. Given the power of the 
study to detect $6 \%$ of the explained variance, the association between TOI and the primary variable of interest, $\mathrm{SvhO}_{2}$, is poor. Controlling for potential confounding variables did not change these results.

Subgroup analysis for cyanotic and non-cyanotic cardiac patients showed that most of the explained variance occurred in cyanotic patients, but there was no significant association between TOI and $\mathrm{SvhO}_{2}$ in either subgroup.

\section{Discussion}

We evaluated transcutaneous SRS for non-invasive assessment of liver tissue oxygenation in infants and children, as an alternative to measuring $\mathrm{SvhO}_{2}$.

The study suggests that transcutaneous NIRS tissue oxygenation measured with an optode placed over the palpable liver did not correlate with invasively measured $\mathrm{SvhO}_{2}$ but was affected by non-hepatic variables, such as arterial oxygen saturation, systemic vascular resistance and cardiac output.

Measurement of hepatic tissue oxygenation is an upcoming technique to monitor adequacy of liver tissue oxygenation in critically ill patients. For these purposes, assessment of $\mathrm{SvhO}_{2}$ is used by some intensive care units. ${ }^{3}$ The technique is suggested to be helpful in the management of patients at risk of hepatic failure after hepatic surgery, of patients with sepsis and of patients requiring high levels of end-expiratory pressures or catecholamine therapy. ${ }^{14-20} \mathrm{SvhO}_{2}$ has been shown to correlate well with gastric intramucosal $\mathrm{pH}$ in patients during cardiac surgery. ${ }^{20}$ However, monitoring $\mathrm{SvhO}_{2}$ is an invasive procedure and, beside problems with vessel puncture and catheter-related infections, the method increases the patients' risk of arrhythmia from catheter dislocation and hepatic vein thrombosis, an issue particularly relevant in children. In addition, catheter placement requires bedside fluoroscopic or ultra-sonographic guidance and technical skills. ${ }^{21}$

Measurement of hepatic tissue oxygenation by NIRS represents a non-invasive approach to assess hepato- splanchnic perfusion and oxygenation. Several authors have reported on NIRS measurement of liver tissue oxygenation..$^{9-11,22-25}$ Most of these studies were performed in animals, with the NIRS probe attached to the liver surface after laparotomy. The investigators mainly studied relative changes of liver tissue oxygenation during naso-gastric feeding, induced hypovolemia, low cardiac output, graded hypoxia or hepatic vascular in-flow occlusion. Of particular relevance to potential clinical applications were the data by ElDesoky and coworkers, who found a direct correlation between hepatic tissue hypoxia measured by liver surface NIRS in pigs and hepatic vein oxygen partial pres- sure during induced hypoxic hypoxemia. ${ }^{11}$ However, in contrast to the promising animal experiments, our data show that, in children up to eight years of age, transcutaneously measured NIRS tissue oxygenation with an optode placed over the palpable liver does not correlate at all with the invasively determined $\mathrm{SvhO}_{2}$.

We propose the following possible explanations for the failure to show any agreement between the two techniques in our study. First, in contrast to the study of El-Desoky, we did not compare intra-individual differences during induced hypoxia. Instead, we evaluated near-infrared SRS for inter-individual single point assessment of hepatic tissue oxygenation compared with $\mathrm{SvhO}_{2}$ in patients with a large range of arterial and hepatic oxygen saturation $\left(\mathrm{SaO}_{2}: 54.0 \%\right.$ to $100.0 \%$; $\mathrm{SvhO}_{2}: 32.1 \%$ to $80.6 \%$ ). Second, measurement of tissue oxygenation by NIRS provides an average value of arterial, venous and capillary blood in the underlying tissue and includes only a small area of the liver, while $\mathrm{SvhO}_{2}$ represents the global balance between hepatic oxygen delivery and oxygen consumption in the tissue. This seems to be an important issue, when NIRS tissue oxygenation is compared with oxygen saturation in the venous outflow of a specific organ or vascular region. ${ }^{26}$ Third, it should be kept in mind that, in cyanotic cardiac patients, adaptive mechanisms regarding splanchnic blood flow and oxygen extraction may affect distribution of blood in the liver and may, therefore, be a contributing factor. Fourth, the fact that TOI was greatly influenced by systemic variables, such as arterial oxygen saturation, vascular resistances and, to a lesser extent, by inferior caval $\mathrm{SO}_{2}$ and cardiac output, implies that the NIRS method used reflects global tissue oxygenation rather than tissue oxygenation in the liver. The findings support our earlier reports on the relationship between TOI measurements over the palpable liver and invasively measured $\mathrm{SvO}_{2}$ found in another study population of 100 critically ill children. ${ }^{10}$

Fifth, transcutaneous NIRS measurement over the palpable liver below the costal arch does not always guaranty assessment of tissue oxygenation in the liver. Although the liver was palpated below the costal arch (at least $2 \mathrm{~cm}$ ) and allowed placement of the NIRS probes in all our intubated and mechanically ventilated patients, it is likely that measurements are obtained from a thin wedge of liver and underlying other organ tissues. This represents an important limitation to the use of the method in sedated or awake, non-intubated and non-ventilated children, in whom mean projection of the liver edge has been reported to be about 1 $\mathrm{cm}$ below the costal margin at end-expiration. ${ }^{27}$

Sixth, it is conceivable that the probe's measuring depth of about $4 \mathrm{~cm}$ is insufficient to specifically 
reflect liver tissue oxygenation, and that in our study NIRS actually returned a value dominated by the arterial oxygenation of the tissue between the sensor and the liver surface. If this holds true, inter-individual variation of thickness and composition of subcutaneous tissue, muscles and ascites may have affected NIRS measurements. The finding of a trend towards higher TOI values with increasing body weight and length lends support to this hypothesis.

The clinical implication of our findings is that transcutaneous single point measurement of TOI with an optode placed over the palpable liver cannot be used to assess liver oxygenation as an alternative to measuring $\mathrm{SvhO}_{2}$. Quantitative short-time assessment of hepatic tissue oxygenation in clinical practice using NIRS seems to be limited to liver surface measurement as reported during liver surgery. ${ }^{28}$ Probably, in the future, NIRS devices with an adjustable angle of light emission-detection and an adaptable depth of measurement, combined with an ultra-sonographic imaging probe will allow the detection of underlying tissues and to focus measurement of oxygenaton to the tissue of interest.

Placing the NIRS probes in an intercostal space would provide an alternative "window to the underlying liver" even if the liver may be not palpable below the costal margin. However, air-filled lung tissue and varying distances between the NIRS probe and liver tissue during spontaneous and artificial ventilation did not further support the use of this approach. In addition, the space between the ribs is narrow in children and an initially well placed NIRS probe in an intercostal space may be easily dislodged and cover a rib if the position of the right upper arm is changed during the procedure. Finally, probes positioned on the lateral thoracic wall would impair lateral $x$-ray investigations during cardiac catheterization.

Recently, an alternative site for NIRS measurement of splanchnic oxygenation was reported by Petros et al. These investigators positioned the NIRS optodes on the abdomen just below the umbilicus and demonstrated that transcutaneous single point NIR measurement of splanchnic/cerebral oxygenation ratio (after an equilibration period of five minutes) was highly sensitive for detecting splanchnic ischemia in neonates. ${ }^{29,30}$ Further studies employing transcutaneous NIRS monitoring of hepato-splanchnic oxygenation will have to elucidate if these non-invasive techniques using alternative placement approaches may yield clinically useful data for monitoring systemic or splanchnic tissue oxygenation, as compared to measurements of central or mixed venous oxygen saturation, continuous cardiac output or gastric tonometry.
In conclusion, transcutaneously NIRS measured tissue oxygenation with an optode placed over the palpable liver does not correlate with $\mathrm{SvhO}_{2}$. The value is mainly determined by non-hepatic measures such as arterial saturation and vascular resistances.

\section{References}

1 Landow L, Andersen LW. Splanchnic ischaemia and its role in multiple organ failure. Acta Anaesthesiol Scand 1994; 38: 626-39.

2 Mythen MG, Webb AR. The role of gut mucosal hypoperfusion in the pathogenesis of post-operative organ dysfunction. Intensive Care Med 1994; 20: 203-9.

3 De Backer D, Vincent JL. Why, when, and how to insert a hepatic vein catheter in critically ill patients. Crit Care Med 1999; 27: 1680-1.

4 Metzler $H$. Continuous measurement of hepatic vein oxygen saturation with a new catheter (Letter).

Intensive Care Med 1992; 18: 131-3.

5 Arnold J, Hendriks J, Ince C, Bruining H. Tonometry to assess the adequacy of splanchnic oxygenation in the critically ill patient. Intensive Care Med 1994; 20: 452-6.

6 Kolkman JJ, Otte JA, Groeneveld ABJ. Gastrointestinal luminal $\mathrm{P}_{\mathrm{CO} 2}$ tonometry: an update on physiology, methodology and clinical applications. Br J Anaesth 2000; 84: 74-86.

7 Wahr JA, Tremper KK, Samra S, Delpy DT. Nearinfrared spectroscopy: theory and applications. J Cardiothorac Vasc Anesth 1996; 10: 406-18.

8 Owen-Reece H, Smith M, Elwell CE, Goldstone JC. Near infrared spectroscopy. Br J Anaesth 1999; 82: 418-26.

9 Teller J, Schwendener K, Wolf $M$, et al. Continuous monitoring of liver oxygenation with near infrared spectroscopy during naso-gastric tube feeding in neonates. Schweiz Med Wochenschr 2000; 130: 652-6.

10 Schulz G, Weiss $M$, Bauersfeld $U$, et al. Liver tissue oxygenation as measured by near-infrared spectroscopy in in the critically ill child in correlation with central venous oxygen saturation. Intensive Care Med 2002; 28: 184-9.

11 El-Desoky AEH, Jiao LR, Havlik R, Habib N, Davidson $B R$, Seifalian $A M$. Measurement of hepatic tissue hypoxia using near infrared spectroscopy: comparison with hepatic vein oxygen partial pressure. Eur Surg Res 2000; 32: 207-14.

12 Matcher SJ, Kirkpatrick P, Nabid K, Cope M, Delpy DT. Absolute quantification methods in tissue near infrared spectroscopy. Proc SPIE 1995; 2389: 486-95.

13 Suzuki S, Takasaki S, Ozaki T, Kobayashi $\Upsilon$. A tissue oxygenation monitor using NIR spatially resolved spectroscopy. Proc SPIE 1999; 3597: 582-92. 
14 Dabn MS, Lange P, Lobdell K, Hans B, Jacobs LA, Mitchell RA. Splanchnic and total body oxygen consumption differences in septic and injured patients. Surgery 1987; 101: 69-80.

15 Dahn MS, Lange MP, Jacobs LA. Central mixed and splanchnic venous oxygen saturation monitoring. Intensive Care Med 1988; 14: 373-8.

16 Ruokonen E, Uusaro A, Alhava E, Takala J. The effect of dobutamine infusion on splanchnic blood flow and oxygen transport in patients with acute pancreatitis. Intensive Care Med 1997; 23: 732-7.

17 Trager K, Radermacher P, Georgiff $M$. PEEP and hepatic metabolic performance in septic shock. Intensive Care Med 1996; 22: 1274-5.

18 Takano H, Matsuda H, Kadoba K, et al. Monitoring of hepatic venous oxygen saturation for predicting acute liver dysfunction after Fontan operations. J Thorac Cardiovasc Surg 1994; 108: 700-8.

19 Kainuma M, Nakashima K, Sakuma I, et al. Hepatic venous hemoglobin oxygen saturation predicts liver dysfunction after hepatectomy. Anesthesiology 1992; 76: 379-86.

20 Landow L, Phillips DA, Heard SO, Prevost D, Vandersalm TJ, Fink MP. Gastric tonometry and venous oximetry in cardiac surgery patients. Crit Care Med 1991; 19: 1226-33.

21 Dahn MS, Ballerstadt R, Lange MP, Schultz J.

Development of a percutaneous fiberoptic hepatic venous localization catheter. Crit Care Med 1999; 27 : 1598-1602.

22 Kitai T, Tanaka A, Tokuka A, et al. Quantitative detection of hemoglobin saturation in the liver with nearinfrared spectroscopy. Hepatology 1993; 18: 926-36.

23 El-Desoky AEH, Seifalian AM, Davidson BR. Effect of graded hypoxia on hepatic tissue oxygenation measured by near infrared spectroscopy. J Hepatol 1999; 31: 71-6.

24 Rhee P, Langdale L, Mock C, Gentilello LM. Nearinfrared spectroscopy: continuous measurement of cytochrome oxidation during hemorrhagic shock. Crit Care Med 1997; 25: 166-70.

25 Beilman GJ, Groebler KE, Lazaron V, Ortner JP. Nearinfrared spectroscopy measurement of regional tissue oxyhemoglobin saturation during hemorrhagic shock. Shock 1999; 12: 196-200.

26 Ali MS, Harmer M, Vaughan RS, Dunne JA, Latto IP. Spatially resolved spectroscopy (NIRO-300) does not agree with jugular bulb oxygen saturation in patients undergoing warm bypass surgery. Can J Anesth 2001; 48: 497-501.

27 McNicholl B. Palpability of the liver and spleen in infants and children. Arch Dis Child 1957; 32: $438-40$.
28 Kitai T, Tanaka A, Tokuka A, et al. Intraoperative measurement of graft oxygenation state in living related liver transplantation by near infrared spectroscopy. Transpl Int 1995; 8: 111-8.

29 Petros AJ, Heys R, Tasker RC, Fortune PM, Roberts I, Kiely $E$. Near infrared spectroscopy can detect changes in splanchnic oxygen delivery in neonates during apnoeic episodes (Letter). Eur J Pediatr 1999; 158: 173.

30 Fortune PM, Wagstaff M, Petros AJ. Cerebro-splanchnic oxygenation ratio (CSOR) using near infrared spectroscopy may be able to predict splanchnic ischaemia in neonates. Intensive Care Med 2001; 27: 1401-7. 